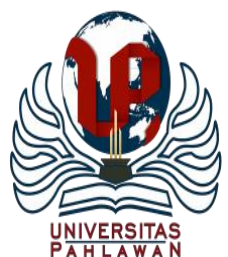

Jurnal Abdidas Volume 2 Nomor 3 Tahun 2021 Halaman 545-550

JURNAL ABDIDAS

http://abdidas.org/index.php/abdidas

\title{
Pelatihan Baca Al-Qur'an (Tahsin) bersama Pimpinan Cabang Istimewa Muhammadiyah Kuala Lumpur Malaysia
}

\author{
Zulherman $^{1 \bowtie}$ Amirudin $^{2}$, Aslam $^{3}$ \\ Pendidikan Guru Sekolah Dasar, Universitas Muhammadiyah Prof.DR.HAMKA, Indonesia ${ }^{1,2,3}$ \\ E-mail: zulherman@uhamka.ac.id ${ }^{1}$, amirudin@uamka.ac.id ${ }^{2}, \underline{\text { ea_aslam@uhamka.ac.id }}{ }^{3}$
}

\begin{abstract}
Abstrak
Pendidikan secara formal sangat berorientasi pada akademik saja, aspek keahlian dalam bacaan shalat dan kemampuan ibadah secara umum didapatkan dari dunia pendidikan lembaga keagamaan seperti madrasah. Saat ini masih banyak sekali umat islam yang belum lancar membaca Al-Qur'an secara baik dan benar, padahal secara usia sudah dewasa. Namun, tidak ada kata terlambat dalam belajar. Pada kegiatan ini, kami mencoba melakukan pelatihan baca Al-Qur'an dengan panduan ustad yang hapal Al-Qur'an. Metode yang diberikan berupa materi singkat dan tips membaca dengan kaidah tajwid. Hasil menunjukan dari 18 orang peserta yang hadir, diperoleh hasil yang signifikan dalam memahami dan mempraktikkan bacaan Al-Qur'an. Hal ini menunjukkan bahwa pada dasarnya, jika belajar dan fokus serta langsung dipraktikkan akan cepat berhasil, sehingga butuh konsistensi dalam membaca Al-Qur'an secara rutin harian. Bertujuan untuk menjaga kaidah tajwid dan pelafalan agar semakin baik dan berkualitas.
\end{abstract}

Kata kunci: pendidikan, tahsin, tajwid

\begin{abstract}
Formal education is very academically oriented, aspects of expertise in reading prayers and worship skills are generally obtained from the education world of religious institutions such as madrasas. Currently, there are still many Muslims who are not fluent in reading the Qur'an properly and correctly, even though they are adults. However, it is never too late to learn. In this activity, we tried to conduct training in reading the Qur'an with the guidance of a cleric who memorized the Qur'an. The method given is in the form of short material and tips for reading with tajwid rules. The results showed that of the 18 participants who attended, significant results were obtained in understanding and practicing the reading of the Qur'an. This shows that basically if you study and focus and immediately put it into practice, you will succeed quickly, so you need consistency in reading the Koran on a daily basis. Aims to maintain the rules of recitation and pronunciation to be better and of higher quality.
\end{abstract}

Keywords: education, tahsin, tajwid

Copyright (c) 2021 Zulherman, Amirudin, Aslam

$\triangle$ Corresponding author

Address : Tanah Merdeka, Pasar Rebo, Jakarta Timur

ISSN 2721- 9224 (Media Cetak)

Email : zulherman@uhamka.ac.id

DOI : https://doi.org/10.31004/abdidas.v2i3.320

ISSN 2721- 9216 (Media Online) 
546 Pelatihan Baca Al-Qur'an (Tahsin) bersama Pimpinan Cabang Istimewa Muhammadiyah Kuala Lumpur Malaysia - Zulherman, Amirudin, Aslam

DOI: https://doi.org/10.31004/abdidas.v2i3.320

\section{PENDAHULUAN}

Generasi muda penerus bangsa semakin tidak mengenal bangsanya sendiri. Nilai kepedulian dan rasa cinta tanah air mulai memudar dari sanubari masyarakat. Salah satu sebab adalah karena sistem pendidikan yang selama ini berjalan masih kurang tepat dan masih kurang sesuai dengan kepribadian bangsa Indonesia. Pendidikan saat ini lebih berfokus pada nilai akademik saja, sedangkan yang menyangkut pendidikan moral spiritual belum menjadi fokus perhatian. Hal tersebut sangat kontras dengan kepribadian bangsa Indonesia yang memegang teguh nilai adat ketimuran dan mempunyai nilai spiritualisme tinggi (Mannuhung \& Hasbar, 2021).

Melihat berkembangnya krisis moral yang terjadi saat ini tentu dengan adanya suatu pendidikan religi menjadi salah satu solusi terbaik untuk menyelamatkan karakter generasi penerus bangsa ini. Sebagai bangsa dengan mayoritas penduduk beragama Islam, maka pendidikan keagamaan dan akhlak dapat dimulai sejak usia dini. Pendidikan religi pada anak usia dini dapat dilakukan secara informal melalui keluarga maupun lingkungan sosial masyarakat melalui Lembaga Pendidikan Al-Qur'an (Nopiyanti et al., 2018).

Lembaga Pendidikan Al-Qur'an (LPA) adalah unit pendidikan non-formal jenis keagamaan berbasis komunitas muslim yang menjadikan Al-Qur'an sebagai materi utamanya dan diselenggarakan dalam suasana yang indah, bersih, rapi, nyaman dan menyenangkan. Tujuan ini untuk menyiapkan terbentuknya generasi yang memiliki komitmen terhadap Al-Qur'an sebagai sumber perilaku, pijakan hidup dan rujukan segala urusannya (Muhammad Aman Ma'mun, 2019). Hal ini ditandai dengan kecintaan yang mendalam terhadap Al-Qur'an mampu dan rajin membacanya dan mempelajari isi kandungan dan memiliki kemauan yang kuat untuk mengamalkannya secara kaffah dalam kehidupan sehari-hari lembaga Pendidikan Al-Qur'an (LPA) Kampong Bahru Kuaala Lumpur, Malaysia ini baru saja awal tahun 2020 dibentuk, di bawah bidang Pendidikan Dakwah Islam, PCIM, Kuala Lumpur, Malaysia. LPA ini sudah banyak sekali peserta yang antusias mengikuti pelatihan membaca Al-Qur'an khususnya untuk usia sekolah dasar dan menengah saja. Sasaran utamanya adalah warga Indonesia usia dewasa yang bermukim di sekitar Kampung Bahru, namun ada juga warga negara setempat yang ikut. Ini juga menjadi poin penting untuk media dakwah Muhammadiyah dan pelatihan baca Al-Qur'an dan penulisan dilakukan dengan daring atau Zoom karena kondisi lockdown.

Hal lainnya juga penting adalah ketersedian tempat untuk LPA, saat ini masih menggunakan sekretariat PCIM atau biasa disebut rumah dakwah Muhammadiyah. Dengan peralatan dan kelengkapan yang ada, sudah dimulai untuk proses pelatihan membaca Al-Qur'an. Kebutuhan lainnya adalah SDM pengajar Al-Qur'an yang tidak tetap. Ini karena saat ini masih menggunakan tenaga relawan dari para kader Muhamadiyah yang mempunyai waktu luang akhir pekan, sehingga perlu sekali untuk mencari SDM tetap guna tetap berjalannya proses pembelajaran baca Al-Qur'an.

Berdasarkan permasalahan di atas, yang kami tawarkan adalah memberikan pelatihan 
547 Pelatihan Baca Al-Qur'an (Tahsin) bersama Pimpinan Cabang Istimewa Muhammadiyah Kuala Lumpur Malaysia - Zulherman, Amirudin, Aslam

DOI: https://doi.org/10.31004/abdidas.v2i3.320

membaca Al-Qur'an yang meliputi: pemahaman tentang huruf hijaiyah, keterampilan membaca sambung huruf hijaiyah, keterampilan ilmu tajwid, untuk jadwal rutin/tetap disesuaikan dengan musyawarah pengurus PCIM Malaysia.

\section{METODE}

Dalam pengabdian ini, kami mencoba memberikan metode pelatihan membaca $\mathrm{Al}$ Qur'an yang meliputi: pemahaman tentang huruf hijaiyah, keterampilan membaca sambung huruf hijaiyah, keterampilan ilmu tajwid, untuk jadwal rutin/tetap disesuaikan dengan musyawarah pengurus PCIM Malaysia

Kegiatan ini dilaksanakan Sabtu, 9 Mei 2020 pukul 09.00-12.00 WIB. Kegiatan dilakukan secara daring menggunakan Zoom Meeting. Moderator membuka acara dan membacakan susuan acara singkat sebelum dibuka atau pembukaan oleh Ketua PCIM dan Sekretaris LPPM UHAMKA.

Peserta yang terdaftar dalam kegiatan pelatihan ini diikuti oleh 25 orang mahasiswa/i asal Indonesia yang saat ini sedang berkuliah di Malaysia (mendaftar), namun hanya 18 orang saja yang mengikuti sampai akhir kegiatan, sebab 7 orang peserta izin karena ada kegiatan lainnya. Dalam pelaksanaan teknis dilakukan secara virtual via Zoom karena masih dalam kondisi pandemik.

Kegiatan pada acara inti yaitu pretest baca Al-Qur'an, lalu penyampaian materi oleh Ust.Jauharul Chitam,S.Pd (Al-Hafiz Qu'ran), dan terakhir ada post-test sebagai penilaian akhir, dimana tiap peserta diminta membaca 1-2 ayat dan di evaluasi hasil bacaan tersebut.
Tabel 1. Target dan Luaran

\begin{tabular}{|c|c|c|c|}
\hline No & Kondisi Awal & Sebelum & Sesudah \\
\hline 1 & $\begin{array}{l}\text { Pemahaman } \\
\text { huruf hijaiyah }\end{array}$ & Kurang & Meningkat \\
\hline 2 & $\begin{array}{l}\text { Keterampilan membaca } \\
\text { sambung huruf hijaiyah }\end{array}$ & Kurang & Meningkat \\
\hline 3 & $\begin{array}{l}\text { Keterampilan ilmu tajwid } \\
\text { dasar }\end{array}$ & Kurang & Meningkat \\
\hline (1) & $\begin{array}{l}\text { Evaluasi tiap pekanan } \\
\text { (kehadiran dan kemajuan } \\
\text { bacaan) }\end{array}$ & Tidak ada & Ada \\
\hline 5 & Jadwal rutin/tetap & Tidak ada & Ada \\
\hline
\end{tabular}

\section{HASIL DAN PEMBAHASAN}

Pelaksanaan acara diawali dengan pembukaan Tilawah Al-Qur'an oleh Ust.Ahmad Fatonidari pengurus PCIM Malaysia. Setelah itu, acara dibuka secara resmi oleh Ketua PCIM Malaysia, Prof.Dr.Sony Zulhuda, beliau seorang dosen di IIUM Malaysia. Beliau sangat mengapresiasi kegiatan tahsin ini dan berterima kasih kepada LPPM UHAMKA, yang masih terus bersinergi dalam kegiatan Bersama PCIM Malaysia dan berharap ada tindak lanjut dari kegiatan ini selanjutnya. Kemudian pembukaan dari UHAMKA disampaikan oleh Dr.Gufron Amirulloh, beliau sekretaris LPMM UHAMKA, yang ikut sebagai peserta dalam kegiatan ini, beliau berpesan dalam bulan Ramadan dimana AlQur'an diturunkan sebagai wahyu kepada Nabi Muhammad SAW memberikan semangat bahwa momentum Ramadan memberikan semangat untuk terus beramal karena pahala yang Allah berikan begitu berkali lipat dari bulan yang lain (Srijatun, 2017).

A. Materi 1: Interaksi Ulama dengan Al-Qur'an di Bulan Ramadan, Sumber Hadist-Hadist Shohih. 
548 Pelatihan Baca Al-Qur'an (Tahsin) bersama Pimpinan Cabang Istimewa Muhammadiyah Kuala Lumpur Malaysia - Zulherman, Amirudin, Aslam

DOI: https://doi.org/10.31004/abdidas.v2i3.320

Dalam materi ini ada 4 hadis penguat bahwa Alquran sangat istimewa bagi umat islam (Agustina et al., 2018; Wan Mohd Yusuf Wan Chik et al., 2018).

1) Hadist pertama "Sebaik-baiknya kalian adalah orang yang belajar Al-Qir'an dan mengamalkannya" (HR.Bukhori). Makna nya adalah dalam proses belajar Alqur'an, kita diminta untuk menyiapkan waktu khusus di samping aktivitas kesibukan dunia, kemudian diminta bersabar dalam mempelajari bacaan AlQur'an, karena jika kita mahir maka akan sempurna baik pila nilai pahala yang di dapat, namun jika masih banyak kekurangan maka Allah tetap memberikan pahala sebesar kesabaran dan komitmen dalam mempelajarinya.

2) Hadist kedua: "Rasullah bersabda; barangsiapa yang membaca Al-Qur'an maka akan mendapatkan 10 kebaikan setiap huruf. (HR;At-Tirmidzi).

Penjelasan hadis ini adalah pahala yang Allah berikan dalam setiap huruf dengan 10 kebaikan, maka semakin banyak ayatayat dibaca maka akan semakin besar pula yang didapat, ini salah satu keistimewaan membaca Al-Qur'an.

3) Hadist ketiga: "Orang yang membaca AlQuran dan ia benar dalam membacanya maka akan dikelilingi oleh para malaikat. Dan orang yang terbata-bata dalam membaca, maka ia akan mendapat dua pahala. (HR: Muttafaqun Alaih)
Makna dari hadist yaitu Allah menjaga diri dari seseorang yang pandai membaca Al-Qur'an dan menjaga dengan para malaikat agar senantiasa dekat dengan Al-Qur'an, dan Allah juga memberikan pahala bagi mereka yang masih dalam proses belajar membaca Al-Qur'an.

4) Hadist ke-4: "Bacalah Al-Qur'an, karena dia akan datang sebagai penolong di hari kiamat". (HR Muslim)

Makna hadis ini yaitu Allah memberikan karunia bagi orang yang rajin dan konsisten dalam membaca Al-Qur'an, karena di hari kiamat Al-Qur'an akan bersaksi sebagai penolong bagi siapa saja yang terbiasa membaca dan mengamalkan.

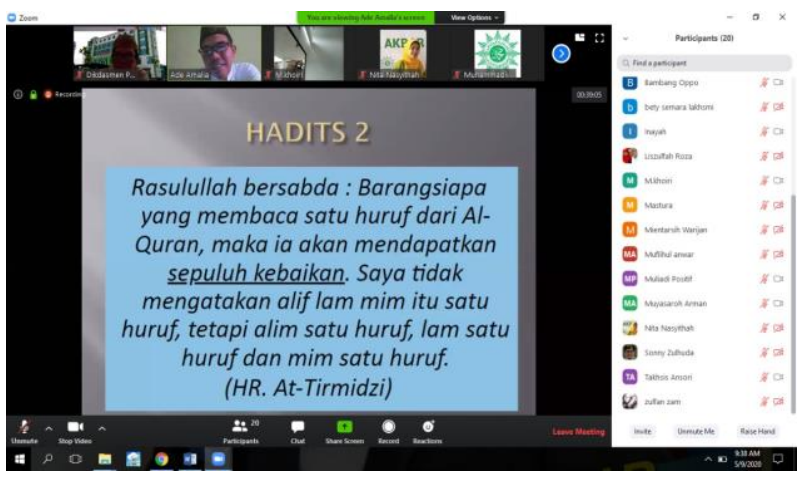

Gambar 1. Penyampaian Materi Kegiatan

B. Materi Kedua: Hukum Bacaan Al-Qur'an

1) Makharijal huruf

Ketartilan atau kefasihan dalam membaca huruf Al-Qur'an sesuai kaidah sebenarnya.

2) MAD/ Panjang Pendek 
Tanda baca untuk hukum panjang atau pendek dalam sebuah ayat yg terdiri atas beberapa gabungan huruf

3) WAQAF

Tanda berhenti, tergantung jenisnya dimana ada saat kita harus berhenti dan tidak.

4) Ayat Gharibah

Tanda baca berhenti sejenak, namun tanpa mengambil nafas dan langsung menyambung huruf bacaan selanjutnya.

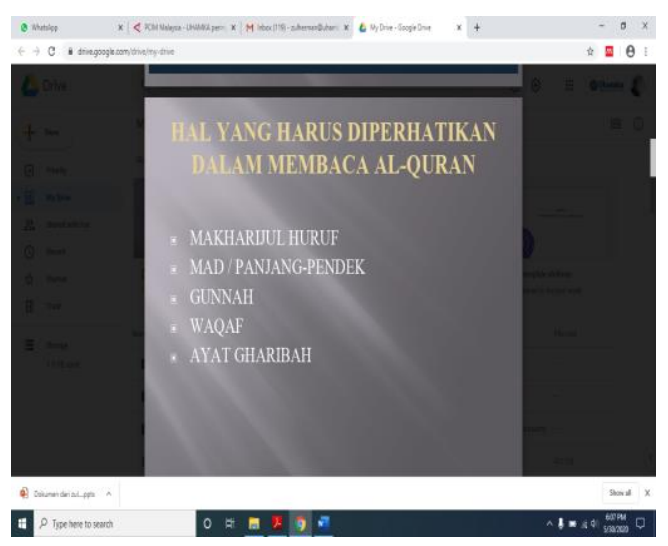

Gambar 2. Isi Materi Kegiatan

Program pengabdian masyarakat AIKA ini dengan tahsin Al-Qur'an ini sangat di respon baik oleh kedua pihak, baik tuan rumah PCIM dan LPPM UHAMKA serta peserta warga Muhammadiyah dari Malaysia, karena jarang sekali kegiatan seperti ini, lebih banyak ke kajian tafsir dan kajian siroh lainnya. Sehingga dari peserta ingin ada kelanjutan pasca ramadan untuk kegiatan tahsin Al-Qur'an dan Insya Allah PCIM akan melakukan tindak lanjut.

Berdasarkan hasil tes akhir baca Al-Qur'an di akhir kegiatan dari 18 orang peserta yang hadir sampai akhir diperoleh data, dan sebagai berikut:
Tabel 2.

\begin{tabular}{llc}
\hline No & \multicolumn{1}{c}{ Hasil Akhir } & Presentase (\%) \\
\hline 1 & $\begin{array}{l}\text { Pemahaman tentang huruf } \\
\text { ijaiyah }\end{array}$ & 80 \\
2 & $\begin{array}{l}\text { Keterampilan membaca } \\
\text { sambung huruf ijaiyah }\end{array}$ & 80 \\
3 & $\begin{array}{l}\text { Keterampilan ilmu tajwid } \\
\text { dasar }\end{array}$ & 90 \\
4 & $\begin{array}{l}\text { Rencana tindak lanjut tiap } \\
\text { pekanan (kehadiran dan } \\
\text { kemajuan bacaan) }\end{array}$ & 80 \\
\hline
\end{tabular}

Dari aspek di atas merupakan hasil yang diperoleh langsung oleh peserta setelah mengikuti ujian tes baca Al-Qur'an, sehingga terlihat kemampuan sebenarnya setelah mengikuti kegiatan ini. Ada peningkatan kenaikan yang signifikan dari semua aspek.

\section{SIMPULAN}

Melihat hasil akhir setelah kegiatan, ternyata diketahui bahwa ada 3 aspek penting: 1) peningkatan kualitas baca Al-Qur'an peserta menjadi lebih baik, 2) Pemahaman ilmu tajdwid lebih baik dari sebelumnya, 3) peserta terlihat sangat antusias selama kegiatan. Dengan ini kegiatan memberikan dampak positif, walaupun dalam suasana pandemik, peserta sangat puas, maka perlu ada kelanjutan kegiatan dan juga menambah keikutsertaan peserta yang belum hadir.

\section{UCAPAN TERIMA KASIH}

Dengan terlaksana kegiatan ini dengan lancar, maka kami berterima kasih kepada Lembaga Pengabdian dan Pemberdayaan masyarakat (LPPM) Universitas Muhammadiyah Prof. DR. HAMKA (UHAMKA), Indonesia dan 
550 Pelatihan Baca Al-Qur'an (Tahsin) bersama Pimpinan Cabang Istimewa Muhammadiyah Kuala Lumpur Malaysia - Zulherman, Amirudin, Aslam

DOI: https://doi.org/10.31004/abdidas.v2i3.320

Pimpinan Cabang Istimewa Muhammadiyah (PCIM) Kuala Lumpur, Malaysia, atas segala fasilitas yang diberikan sehingga kegiatan berjalan dengan lancar, dan terimakasih juga kepada para peserta yang telah meluangkan waktu untuk mengikuti kegiatan secara baik, semoga menjadi amal sholeh kita semua.

\section{DAFTAR PUSTAKA}

Agustina, S., Sakethi, D., Prabowo, R., \& Andrian, R. (2018). Optimasi Pencarian Kata-Kata Dalam Empat Kitab Hadis. Jurnal Komputasi, $\quad 6(1), \quad 1-7$. https://doi.org/10.23960/komputasi.v6i1.165 4

Mannuhung, S., \& Hasbar, H. (2021). Peningkatan Mutu Pembelajaran Pendidikan Agama Islam (Pai) Melalui Kegiatan Ceramah (Da'wah), Pidato Dan Baca Tulis Qur'an (Btq) Dan Dzikir Bersama Pada ... Genta Mulia: Jurnal Ilmiah ..., XII(1), 197-210.

Muhammad Aman Ma'mun. (2019). Kajian Pembelajaran Baca Tulis Al-Qur'an. Jurnal Pendidikan Islam. https://doi.org/10.37286/ojs.v4i1.31

Nopiyanti, D., Ghofar, A., \& Nawawi, N. (2018). Pengaruh Metode Qiraati terhadap Kemampuan Membaca Al-Qur'an Anak Usia 7-12 Tahun di Taman Pendidikan Al-Qur'an (TPQ) Hidayatus Shibyan Desa Pegagan Lor Kecamatan Kapetakan Kabupaten Cirebon. Al-Tarbawi Al-Haditsah: Jurnal Pendidikan Islam.

https://doi.org/10.24235/tarbawi.v3i1.2855

Srijatun, S. (2017). IMPLEMENTASI PEMBELAJARAN BACA TULIS AL QUR'AN DENGAN METODE IQRA PADA ANAK USIA DINI DI RA PERWANIDA SLAWI KABUPATEN TEGAL. Nadwa https://doi.org/10.21580/nw.2017.11.1.1321

Wan Mohd Yusuf Wan Chik, Abdul Wahab Md Ali, Ahmad Jazlan Jusoh, \& Abdullah Alqari Mohd. Zabudin. (2018). Konsep Kesejahteraan Keluarga Menurut Hadis AL-
SA'ADAH. Asian People Journal (APJ), 1(2), $\quad$ 92-108. www.journals.unisza.edu.my/apj/www.jurnal .unisza.edu.my/apj 